Abstracta Iranica Abstracta Iranica

Revue bibliographique pour le domaine irano-aryen

Volume 23 | 2002

Comptes rendus des publications de 2000

The Cities and routes of the great Silk Road (on Central Asia Documents). Tachkent, International Institute for Central Asian Studies, 1999, $126 \mathrm{p}$.

Étienne de La Vaissière

(2) OpenEdition

1 Journals

Édition électronique

URL : http://journals.openedition.org/abstractairanica/35175

DOI : 10.4000/abstractairanica.35175

ISSN : 1961-960X

Éditeur :

CNRS (UMR 7528 Mondes iraniens et indiens), Éditions de l'IFRI

Édition imprimée

Date de publication : 15 mai 2002

ISSN : 0240-8910

Référence électronique

Étienne de La Vaissière, "The Cities and routes of the great Silk Road (on Central Asia Documents).

Tachkent, International Institute for Central Asian Studies, 1999, 126 p. », Abstracta Iranica [En ligne],

Volume 23 | 2002, document 38, mis en ligne le 08 février 2010, consulté le 25 septembre 2020. URL:

http://journals.openedition.org/abstractairanica/35175; DOI : https://doi.org/10.4000/

abstractairanica.35175

Ce document a été généré automatiquement le 25 septembre 2020.

Tous droits réservés 


\title{
The Cities and routes of the great Silk Road (on Central Asia Documents). Tachkent, International Institute for Central Asian Studies, 1999, 126 p.
}

\author{
Étienne de La Vaissière
}

Ce livre de vulgarisation a l'avantage de présenter en anglais de manière succincte un grand nombre de sites archéologiques centre-asiatiques et de donner un résumé des travaux en russe sur chacun d'entre eux. D'autre part, il est abondamment illustré de cartes et plans de sites extraits de publications parfois fort difficiles à trouver, et il peut à cet égard rendre des services. Quelques références bibliographiques sont indiquées en notes. Le volume se conclut par la traduction de quelques passages de Muqaddasī consacrés à l'Asie centrale, texte effectivement essentiel pour lequel on utilisera de préférence la traduction de Colins (voir Abs. Ir. 17-19, n 172).

INDEX

Thèmes : 3.0. Généralités

\section{AUTEURS}

ÉTIENNE DE LA VAISSIÈRE

ENS - Paris 